
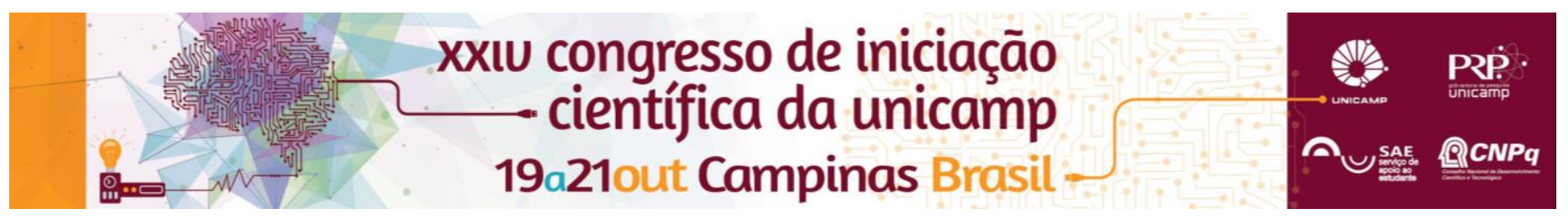

\title{
Método para Avaliação das Técnicas de Policiamento de Tráfego dos Codificadores/Decodificadores Visando o Dimensionamento de Redes de Dados Stream.
}

\section{Bruno Oliveira de Andrade e Silva*, Edson Luiz Ursini.}

\begin{abstract}
Resumo
Este trabalho tem por objetivo levantar informações dos enlaces de rede do campus da FT, e a partir destes dados levantados, é proposta a criação de modelos de simulação por eventos discretos no software de simulação ARENA, os quais estão validados em projeto de pesquisa anterior em comparação com modelos analiticos. O foco será em análise de dados do tipo streampor meio de uma perspectiva que dá enfoque às caracteristicas de policiamento de tráfego e de variações dos atrasos de rede (jitter), além da análise do uso de CODECs (codificadores-decodificadores), assim podendo servir tambem como material de aprimoramento futuro para os enlaces do campus.
\end{abstract}

\section{Palavras-chave:}

Policiamento de Tráfego,Simulação por eventos discretos, Jitter

\section{Introdução}

Um trabalho de IC anterior, [1], avaliou em mais profundidade os serviços do tipo elástico. Este trabalho pretende dar continuidade ao anterior, mas com foco mais específico em tráfego do tipo stream. Serão utilizados dados obtidos por pesquisa na Internet ou por analogia com serviços existentes em redes convencionais (por exemplo, analogia do serviço VolP, voz sobre o protocolo Internet com a telefonia fixa convencional).

Esta iniciação científica vai abordar os aspectos de dimensionamento, mas tendo em vista as características dos CODECs e aspectos de policiamento de tráfego.

$\mathrm{Na}$ Fig. 1 está exemplificada a topologia de uma rede típica (também com alguns serviços típicos). Cabe salientar que enlaces podem ser estudados individualmente e depois, por meio de métodos estatísticos, estender a avaliação para uma rede com múltiplos hops (saltos), por exemplo

\section{Resultados e Discussão}

A Elaboração de modelos como mostra a Fig. 2 serviu para validar os modelos teóricos dos projetos de pesquisa passados em comparação a modelos analiticos e podem ser utilizados para medição de trafego stream que são adequados/calibrados para chegadas Poissonianas. O modelo de simulação vai permitir generalizar os estudos também para chegadas nãopoissonianas. Foram obtidas informações como número de pacotes perdidos e número de pacotes entregues para os serviços de VolP e Videoconferência. As simulações foram feitas a partir de dados reais advindos do campus da faculdade de tecnologia e que são sensiveis a perda de pacotes (serviços elásticos) com exceção dos novos dados para serviço do tipo stream, porque esses serviços ainda não foram contemplados pela infraestrutura do campus. O objetivo é justamente ver como os dados stream afetam as perdas de pacote da rede e a variação do atraso (jitter), além, é claro, da atuação de diferentes CODECs nos mesmos. Em trabalhos futuros podem ser simulados tráfegos com outras características de chegadas, como por exemplo, Weibull ou Lognormal que têm cauda longa (heavy-tail).

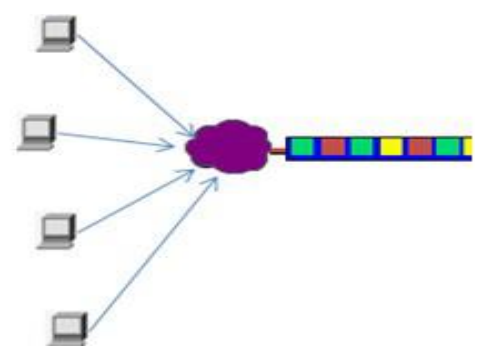

Figura 1. Modelo de um enlace de dados

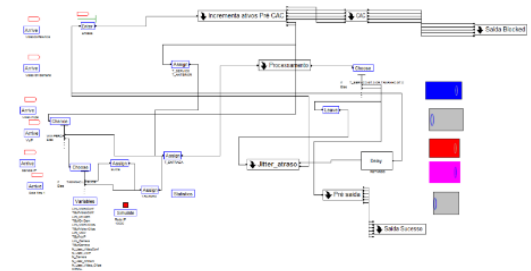

Figura 2. Exemplo de modelo de simulação no Software ARENA

\section{Conclusões}

As simulações realizadas mostram aspectos inerentes à perda de pacote nos âmbitos dos serviços de Videoconferência e VolP, onde uma perspectiva de CODECs (volume de tráfego em bit/s) é simulada por meios matemáticos. O trabalho ainda abrange espaço para melhorias futuras como a adição de políticas de tráfego e efeitos de CODECs diretamente no modelo da aplicação, abrindo margem assim para uma pesquisa mais ampla para efeito de planejamento $e$ dimensionamento de enlace de dados.

\section{Agradecimentos}

Agradecimentos ao orientador Edson Luiz Ursini e a instituição de fomento: PIBIT/FUNTEL

[1] Projeto de Pesquisa PIBITI 2013 "Metodologia de Modelos Analíticos e de Simulação para o Dimensionamento de Redes Dados", Michael Soares da Silva Fonseca

[2] Diório, R. F., V. S. Timóteo, E. L. Ursini, "Testing and IP-based Multimedia Gateway", INFOCOMP, Journal of Computer Science, UF Lavras, ago/2014.

[3]. ITU-T - P.800 Methods for Subjective Determination of Transmission Quality 